\title{
Zinc Metabolism in Adolescents with Crohn's Disease
}

\author{
IAN J. GRIFFIN, SANDRA C. KIM, PENNI D. HICKS, LILY K. LIANG, AND STEVEN A. ABRAMS \\ Section of Neonatology, Department of Pediatrics [I.J.G., S.A.A.], USDA/ARS Children's Nutrition \\ Research Center [I.J.G., S.A.A., P.D.H., L.K.L.], Baylor College of Medicine, Houston, Texas, 77030, \\ U.S.A., and Department of Pediatric Gastroenterolgy, University of North Carolina at Chapel Hill, Chapel \\ Hill, North Carolina, 27599, U.S.A. [S.C.K.]
}

\begin{abstract}
ABST
Low serum zinc concentrations have been reported in Crohn's
disease (CD) and overt zinc deficiency has been described, but
little is known about the effect of CD on zinc metabolism in
adolescents. The aim of this study was to measure zinc absorp-
tion, endogenous fecal zinc excretion, urinary zinc excretion, and
zinc balance in children with stable CD and in matched controls.
Subjects were 15 children, ages $8-18$ y, with stable CD, and 15
healthy matched controls. Subjects were adapted to diets pro-
viding 12 mg/d elemental zinc for 2 wh, and then admitted for a
6-d metabolic study. Stable zinc isotopes were given intrave-
nously and orally, and urine and feces collected for 6 d. Frac-
tional zinc absorption, endogenous fecal zinc excretion, and zinc
balance were calculated using established stable isotope meth-
ods. In subjects with CD, zinc absorption (10.9\% \pm 6.1 versus
\end{abstract}
Crohn's disease (CD) is a chronic, progressive inflammatory disorder that can affect the entire length of the gastrointestinal tract. Children with $\mathrm{CD}$ often present with growth stunting, weight loss, and nutritional deficiencies due to anorexia, poor intestinal absorption, and increased losses of nutrients in the gastrointestinal tract (1).

Zinc is a component of over 200 enzymes and is essential for normal immune function, DNA and RNA synthesis, and gene transcription. Zinc is absorbed along the length of the small intestine and is transported to the liver in the portal circulation. It is excreted into the gut (endogenous fecal zinc

Received September 26, 2003; accepted March 1, 2004.

Correspondence: Ian J. Griffin, M.B. Ch.B., USDA/ARS Children's Nutrition Research Center, 1100 Bates St., Baylor College of Medicine, Houston, TX 77030, U.S.A.; e-mail: igriffin@bcm.edu

This project has been funded in part with federal funds from the USDA/ARS under Cooperative Agreement number 58-6250-6-001 and in part by the Crohn's and Colitis Foundation of America.

This work is a publication of the U.S. Department of Agriculture (USDA)/Agricultural Research Service (ARS) Children's Nutrition Research Center, Department of Pediatrics, Baylor College of Medicine and Texas Children's Hospital, Houston, TX. Contents of this publication do not necessarily reflect the views or policies of the USDA, nor does mention of trade names, commercial products, or organizations imply endorsement by the U.S. government.

DOI: 10.1203/01.PDR.0000132851.50841.D7
$23.4 \pm 15.8, p=0.008)$ and plasma zinc concentration $(0.85$ $\mathrm{mg} / \mathrm{dL} \pm 0.15$ versus $1.25 \pm 0.35, p=0.004)$ were significantly reduced, compared with controls. Despite this, there were no significant differences in endogenous fecal zinc excretion (2.0 $\mathrm{mg} \pm 1.5$ versus $1.5 \pm 1.5, p=0.34$ ) or urinary zinc excretion (0.9 $\mathrm{mg} \pm 0.7$ versus $1.0 \pm 0.7, p=0.47)$. Zinc balance was significantly lower in $\mathrm{CD}(-1.5 \mathrm{mg} \pm 1.5)$ than in controls $(+0.6 \mathrm{mg} \pm 3.1, p<0.0001)$. In conclusion, adolescents with $\mathrm{CD}$ have significantly reduced zinc absorption. Despite this, they were unable to reduce endogenous fecal zinc excretion to restore normal zinc balance and had a significantly worse zinc balance and lower plasma zinc concentration than controls. (Pediatr Res 56: 235-239, 2004)

excretion), and pancreatic and biliary secretions contain large amounts of zinc, most of which is subsequently reabsorbed. Zinc homeostasis is maintained by changes in fractional zinc absorption and in endogenous fecal zinc excretion (2). Endogenous fecal zinc excretion increases during periods of high zinc intake (3) and decreases during periods of zinc restriction (4).

Severe zinc deficiency leads to clinical features of acrodermatitis such as alopecia, anorexia, diarrhea, dermatitis, poor growth, and impaired immune function, and children are at especially high risk for zinc deficiency due to their high requirements for normal growth (2). Zinc deficiency was first reported in CD in the 1970s (5-7), and, in extreme cases, the clinical features of acrodermatitis have been described (8-11). The incidence of milder forms of zinc deficiency has been difficult to assess. Although several investigators have reported low plasma zinc concentrations in patients with $\operatorname{CD}(8,12-18)$, very little body zinc is in the plasma and it is a poor measure of zinc status (2). Some studies have also demonstrated decreases in zinc-dependent enzymes [such as thymulin in the plasma (19) and metallothionein in the gut mucosa (20)], reduction in muscle zinc concentration (19), and poor taste acuity $(6,21)$ in patients with $C D$. 
Zinc deficiency in CD must presumably result from low gastrointestinal absorption or increased zinc losses (either in the urine or feces) because the self-selected diets of adults with $\mathrm{CD}$ typically contain a similar amount of zinc to that consumed by control subjects (22). A number of studies have examined zinc absorption in $\mathrm{CD}$ and have shown either normal $(23,24)$ or low zinc absorption $(17,18,25)$. However, we are unaware of any study that has measured endogenous fecal zinc excretion in $\mathrm{CD}$. Without this data, the absorption measurements are very difficult to interpret because endogenous fecal zinc excretion is an important site of zinc homeostasis. Subjects with CD might adapt to low zinc absorption by reducing endogenous fecal zinc excretion. Alternatively, they may have increased endogenous fecal zinc excretion, increasing their susceptibility to zinc deficiency.

The objectives of the current study were to test the hypotheses that fractional zinc absorption is significantly reduced, and endogenous fecal zinc excretion is significantly increased, in adolescents with $\mathrm{CD}$ when compared with healthy agematched controls.

\section{SUBJECTS AND METHODS}

Study population. Fifteen patients with stable CD, $8-18$ y of age, were recruited from the Inflammatory Bowel Disease Clinic of Texas Children's Hospital, Houston, TX, U.S.A. They were matched one-to-one with healthy age-, ethnicity-, and gender-matched adolescents.

Subjects with CD were considered eligible if they were aged 8-18 y, had a clinical diagnosis of CD, a history of good compliance with medical treatments and clinic visits, and had a CD Activity Index (CDAI) between 150 and 250 (representing stable and relatively nonsevere disease). Subjects were ineligible if they had been hospitalized with an acute exacerbation of $\mathrm{CD}$, required an escalation of medical therapy within 2 mo of the study, had undergone bowel resection, or had received systemic corticosteroids within 2 mo of enrollment. All subjects had previously documented small intestinal disease, either by endoscopic study or contrast radiology.

Controls were considered eligible if they were healthy, not on any regular medications (including vitamin, mineral, and zinc supplements), and were within $1 \mathrm{y}$ of age of their match, the same ethnic group, and the same gender.

Ethical approval was obtained from the Baylor College of Medicine and Affiliated Hospitals Institutional Review Board. Parental consent was obtained in all cases, as was assent (as age appropriate) from the study subject.

Isotope preparation. Zinc-70 ( $74 \%$ enrichment by mass) and zinc-67 (90\% enrichment by mass) produced in Russia were purchased from Trace Sciences Inc. (Toronto, ON, Canada) as the oxide. Aqueous solutions were prepared by the Investigational Drug Service of Texas Children's Hospital as described elsewhere (26). Solutions were tested for sterility before use, and intravenous isotopes were also tested for pyrogenicity.

Study protocol. After informed written consent was obtained, the subjects had a structured interview with a registered dietitian, who estimated their usual zinc intake. If required, a dietary plan was devised to modify the zinc intake to approximately $12 \mathrm{mg} / \mathrm{d}$. Typically, this involved increasing zinc intake by substituting a zinc-fortified breakfast cereal for an unfortified one, increasing chicken or beef intake, or both. At the time the study was carried out, the U.S. recommended dietary allowance (RDA) for zinc was $10 \mathrm{mg} / \mathrm{d}$ for children $7-10 \mathrm{y}, 15 \mathrm{mg} / \mathrm{d}$ for males aged $11-18 \mathrm{y}$, and $12 \mathrm{mg} / \mathrm{d}$ for females 11-18 y (27).

Subjects remained on this diet for $2 \mathrm{wk}$ before being admitted to the General Clinical Research Center of Texas Children's Hospital in Houston, TX, or the Metabolic Research Unit of the Children's Nutrition Research Center, Houston, TX, for a 6-d study period. In the week preceding admission, subjects kept a weighed record of all the food they consumed on two weekdays and one weekend day.

Subjects were admitted at approximately $0700 \mathrm{~h}$ and asked to empty their bladders. They then had $0.5 \mathrm{mg}$ of an aqueous zinc-70 enriched tracer infused intravenously and $5-10 \mathrm{~mL}$ of blood drawn. Blood samples for plasma zinc analysis were collected in zinc-free tubes anticoagulated with ammonium heparin (Monovette $9 \mathrm{~mL}$ AH, Sarstedt, Newton, NC, U.S.A.). Subjects consumed a standard breakfast including $120 \mathrm{~mL}$ of orange juice to which $2.0 \mathrm{mg}$ of an aqueous zinc- 67 enriched tracer had been added 18-24 h earlier. A complete 6-d urine and fecal collection was then begun. Urine was collected and analyzed in 8-h pools. Each fecal collection was analyzed separately.

Diets during the 6-d admission were designed to provide 12 $\mathrm{mg} / \mathrm{d}$ zinc. Complete records of all food and drink consumed during the study period were collected. These records, together with the food records for the $3 \mathrm{~d}$ before admission, were used to calculate the subjects' actual zinc intake using the Minnesota Nutrition Data System (University of Minnesota, version 2.91, Food Database 12A, Nutrition Database 27).

Sample preparation and analysis. Urine and fecal samples were digested in nitric acid, purified using anion exchange columns, and loaded on to rhenium filaments for mass spectrometry analysis as described elsewhere (28). Zinc isotope ratios were measured by thermal ionization magnetic sector mass spectrometry (Finnigan MAT 261, Thermo Finnagan, Bremen, Germany). Ratios were expressed with reference to the nonadministered isotope zinc-66 and mathematically corrected to the zinc-64/zinc-66 ratio to compensate for temperature-specific effects of fractionation (28). This method is capable of measuring isotope ratio with a relative standard deviation of $<0.2 \%$ (29). Isotope ratios were converted to tracer:tracee ratios (TTR) (30). Plasma, fecal, and urinary zinc concentration were measured by atomic absorption spectroscopy. A plasma zinc concentration of $<0.8 \mathrm{mg} / \mathrm{L}$ was taken to be suggestive of suboptimal zinc status.

Measurement of zinc absorption. Zinc absorption was measured using a modification of the dual stable isotope method described by Friel et al. (31) from the ratio of the fractional excretion of the oral and intravenous isotopes in the 8-h urinary aliquot collected $48 \mathrm{~h}$ after tracer administration, using the equation, 


\section{Zinc absorption $=\frac{\text { TTR for oral tracer } / \text { dose of oral tracer }}{\text { TTR for i.v. tracer/dose of i.v. tracer }}$}

Measurement of endogenous fecal zinc excretion. Endogenous fecal zinc excretion was measured using methods previously described for calcium (32), where endogenous fecal zinc excretion is given by

Endogenous fecal zinc excretion $=$

urinary zinc excretion in time $t$

$\times$ fecal excretion of i.v. tracer in time $t$

urinary excretion of i.v. tracer in time $t$

Endogenous fecal zinc excretion was measured from the complete 6-d urine and fecal collection. Two subjects with CD did not collect any feces during the 6-d in-patient study, so endogenous fecal excretion was not calculated for them.

Zinc balance. Approximate zinc balance, ignoring losses in sweat, hair, and desquamated skin cells, was estimated from the equation

Zinc balance $=($ Zinc intake $\times$ fractional zinc absorption $)$

- endogenous fecal zinc excretion - urinary zinc excretion

Statistical analysis. Statistical analysis was carried out using StatView v5.1 for Macintosh (SAS Institute, Cary, NC, U.S.A.). Comparisons between the two groups were made using the unpaired $t$ test (for continuous variables) and the Fisher exact test (for categorical variables). Zinc balance was compared with zero balance using the one-sample $t$ test (hypothesized mean $=0$ ). The relationship between plasma zinc concentration and zinc absorption, endogenous fecal zinc excretion, urinary zinc excretion, and zinc balance was assessed using simple regression analysis. Data are given as mean \pm $\mathrm{SD}$, unless otherwise stated, and statistical significance was assumed at $p<0.05$. Ninety-five percent confidence intervals ( $95 \%$ CI) for the differences between the two groups were calculated.

\section{RESULTS}

Subject characteristics. Fifteen subjects with CD and 15 age-, gender-, and ethnicity-matched controls were recruited. Most CD subjects were receiving treatment with 5-aminosalicilic acid, allopurinol, and acetaminophen or a nonsteroidal anti-inflammatory agent. No subjects were taking oral steroids. Subjects with $\mathrm{CD}$ tended to have lower $\mathrm{Hb}$ concentrations and had significantly higher red cell distribution widths (Table 1). The zinc intakes for the two groups were similar $(12.0 \pm 2.5$ $\mathrm{mg} / \mathrm{d}$ versus $13.5 \pm 2.2 ; p=0.09 ; 95 \% \mathrm{CI},-0.29$ to 3.19 $\mathrm{mg} / \mathrm{d}$ ).

Plasma zinc concentration. Fasting plasma zinc concentration was significantly lower in subjects with $\mathrm{CD}$ than for controls $(0.85 \pm 0.15 \mathrm{mg} / \mathrm{L}$ versus $1.24 \pm 0.35 ; p=0.0003$; $95 \% \mathrm{CI}, 0.19$ to $0.59 \mathrm{mg} / \mathrm{L}$ ). Plasma zinc concentration was $<0.8 \mathrm{mg} / \mathrm{L}$ in three subjects with CD compared with none of the controls ( $p=0.48$, Fisher's exact test).

Zinc absorption, endogenous fecal zinc excretion, and urinary zinc excretion. Zinc absorption in the subjects with $\mathrm{CD}(10.9 \pm 6.1 \%)$ was significantly lower than in the controls subjects $(23.0 \pm 16 \% ; p=0.0003 ; 95 \%$ CI for difference 3.47 to $21.5 \%)$. There was no difference in urinary zinc excretion $(0.86 \pm 0.65 \mathrm{mg} / \mathrm{d}$ versus $1.04 \pm 0.69 ; p=0.47 ; 95 \% \mathrm{CI}$ for difference -0.32 to $0.68 \mathrm{mg} / \mathrm{d}$ ) or in endogenous fecal zinc excretion $(2.0 \pm 1.5 \mathrm{mg} / \mathrm{d}$ versus $1.1 \pm 1.5 ; p=0.34 ; 95 \% \mathrm{CI}$ for difference -1.76 to $0.64 \mathrm{mg} / \mathrm{d}$ ). Zinc balance was significantly negative in the CD subjects $(-1.5 \pm 1.5 \mathrm{mg} / \mathrm{d}$, onesample $t$ test hypothesized mean $=0, p=0.0019)$ and significantly lower than in the control subjects $(0.6 \pm 3.1 \mathrm{mg} / \mathrm{d}$; $p=0.030$ ).

Effect of plasma zinc concentration. There was no significant correlation between plasma zinc concentration and fractional zinc absorption, endogenous fecal zinc excretion, or urinary zinc excretion for either the $\mathrm{CD}$ group or for the control group ( $r^{2}<0.20, p>0.20$ for all comparisons).

Table 1. Baseline blood chemistry values of the Crohn's disease and controls subjects

\begin{tabular}{|c|c|c|c|}
\hline Parameter & Controls & Crohn's disease & $p$ Value \\
\hline Age (y) & $14.8 \pm 1.5$ & $15.4 \pm 1.7$ & 0.35 \\
\hline Height $(\mathrm{cm})$ & $163 \pm 15$ & $159 \pm 11$ & 0.48 \\
\hline Weight (kg) & $61.2 \pm 10.4$ & $54.6 \pm 12.7$ & 0.21 \\
\hline Hematocrit $(\%)$ & $37.7 \pm 4.9$ & $35.4 \pm 3.3$ & 0.16 \\
\hline Mean cell volume (fl) & $82.5 \pm 5.7$ & $83.8 \pm 6.0$ & 0.57 \\
\hline Mean cell hemoglobin (pg) & $28.5 \pm 1.3$ & $28.3 \pm 2.4$ & 0.81 \\
\hline Serum sodium $(\mathrm{mmol} / \mathrm{L})$ & $141 \pm 2$ & $140 \pm 2$ & 0.12 \\
\hline Serum potassium $(\mathrm{mmol} / \mathrm{L})$ & $4.3 \pm 0.1$ & $4.1 \pm 0.4$ & 0.18 \\
\hline Serum chloride $(\mathrm{mmol} / \mathrm{L})$ & $105 \pm 2$ & $103 \pm 4$ & 0.10 \\
\hline Serum bicarbonate $(\mathrm{mmol} / \mathrm{L})$ & $25.3 \pm 1.9$ & $23.8 \pm 3.2$ & 0.18 \\
\hline Blood urea nitrogen $(\mathrm{mg} / \mathrm{dL})$ & $13.0 \pm 3.6$ & $10.7 \pm 4.0$ & 0.12 \\
\hline Creatinine $(\mathrm{g} / \mathrm{dL})$ & $0.7 \pm 0.1$ & $0.6 \pm 0.2$ & 0.13 \\
\hline
\end{tabular}

Continuous variables are given as mean $\pm \mathrm{SD}$ and compared using two-sample $t$-tests. 


\section{DISCUSSION}

We found significant changes in zinc metabolism in children with stable CD compared with healthy age-, gender-, and ethnicity-matched controls. All subjects were adapted to a diet similar to the U.S. RDA for zinc at the time the study was carried out (27) and similar to the usual intakes of children in these age ranges (33). Subjects with $\mathrm{CD}$ had significantly lower fractional zinc absorption, lower plasma zinc, and worse zinc balance than the controls.

Although much remains to be learned about the absorption and cellular uptake of zinc in humans, a recent advance is the identification of a range of zinc/iron-regulated transporters (ZIP) superfamily of proteins (34) that transport a variety of cations in fungi, plants, and humans. They include the SLC39 family of transporters (SLC38A1-A4) (35). The gene SLC39A4 codes for the protein hZIP4 that is highly expressed in stomach, small intestine, and colon. Mutations in this gene have recently been shown to be the cause of the autosomal recessive disease of zinc uptake, acrodermatitis enteropathica $(36,37)$. Although some of the mutations described in this gene would be expected to have very significant effects on protein confirmation and function (38), acrodermatitis enteropathica responds clinically to high-dose zinc supplementation (39). This suggests that other, lower-affinity, or less-specific, transport proteins are involved in gastrointestinal absorption of zinc.

Zinc homeostasis is affected both by fractional zinc absorption and by zinc losses into the gut (endogenous fecal zinc absorption) (40). Studies in swine have demonstrated that an important metabolic adaptation to zinc deficiency is a decrease in zinc losses in pancreatic and biliary secretions (41). This is supported by previous studies of Chinese women that have shown that the principal adaptation to marginal zinc intake is decreased endogenous fecal zinc excretion (4). Therefore, one would expect that the poorer zinc status in the CD children should have led to reduced endogenous fecal zinc excretion. However, this was not the case. It appears that the children with $\mathrm{CD}$ were unable to down-regulate their endogenous fecal zinc excretion. Taken together, these findings suggest that children with $\mathrm{CD}$ are at risk of zinc deficiency due to reduced zinc absorption and an inability to compensate with a reduction in endogenous fecal zinc excretion.

Fasting plasma zinc was lower in the CD subjects than the controls, consistent with other studies in CD with (19) or without gut resection $(6,8,14,16,17,42)$. It has been suggested that the lower plasma (or serum) zinc in CD might result from a lower serum albumin concentration $(12,13)$. However, in our study, the serum albumin concentration was not different between the groups. It appears, therefore, that lower fasting zinc concentration in children with $\mathrm{CD}$ in our study truly reflects poor zinc nutritional status.

Several studies have suggested that urinary zinc excretion is lower in CD patients $(17,42-44)$, presumably as an adaptation to suboptimal zinc status. In our study, urinary zinc excretion was similar in the $\mathrm{CD}$ subjects and the controls. However, we studied subjects with stable CD, so we might have seen a difference in subjects with more severe $\mathrm{CD}$ or with more severe zinc deficiency (45).
The Institute of Medicine estimates that children aged 9-13 y need to absorb $0.2 \mathrm{mg} / \mathrm{d}$ for normal growth, whereas those aged $14-18$ y require $0.2 \mathrm{mg} / \mathrm{d}$ (males) or $0.1 \mathrm{mg} / \mathrm{d}$ (females) (45). If we assume that zinc absorption, endogenous fecal zinc losses, or urinary zinc excretion would not change with increasing zinc intake, children with $\mathrm{CD}$ in our study would need total zinc intakes of $27-28 \mathrm{mg} / \mathrm{d}$ to achieve this. However, such intakes are close to, or above, the tolerable upper limit at these ages $(9-13 \mathrm{y}=23 \mathrm{mg} / \mathrm{d}, 14-18 \mathrm{y}=34 \mathrm{mg} / \mathrm{d})(45)$. The tolerable upper limit is based on possible adverse effects of high zinc intakes on copper status (45). Zinc intakes this high may raise concern for their adverse effect on copper status or retention in children with $\mathrm{CD}$. These intakes cannot, therefore, be recommended without prospective, randomized studies to evaluate the effect of zinc supplementation at this level on zinc balance, copper status, and other markers such as disease activity and immune function.

In summary, this study demonstrates that children with mild stable $\mathrm{CD}$ are at risk of zinc deficiency due to low zinc absorption and inappropriately high endogenous fecal zinc losses. Further studies are needed to determine the optimum level of zinc supplementation for children with CD.

Acknowledgments. The authors thank Dr. George Ferry and the Section of Gastroenterology and Nutrition at Baylor College of Medicine and Texas Children's Hospital for assistance in identifying study patients; Mercedes Villareal and Dorothy Powledge for help in study recruitment; Zhensheng Chen, Yana Kriseman, Lisa Turner, and Christopher Branner for assistance with study performance; and Marlane Kayfes for editorial assistance.

\section{REFERENCES}

1. Kim S, Ferry G 2002 Inflammatory bowel diseases in children. Curr Probl Pediatr Adolesc Health Care 32:108-132

2. King JC, Keen CL 1999 Zinc. In: Shils ME, Olson JA, Shikne M, Ross AC (eds) Modern Nutrition in Health and Disease. Williams and Wilkins, Baltimore, pp 223-240

3. Coppen DE, Davies NT 1987 Studies on the effects of dietary zinc dose on 65Zn absorption in vivo and on the effects of $\mathrm{Zn}$ status on $65 \mathrm{Zn}$ absorption and body loss in young rats. Br J Nutr 57:35-44

4. Sian L, Mingyan X, Miller LV, Tong L, Krebs NF, Hambidge KM 1996 Zinc absorption and intestinal losses of endogenous zinc in young Chinese women with marginal zinc intakes. Am J Clin Nutr 63:348-353

5. Sandstead HH 1973 Zinc nutrition in the Unites States. Am J Clin Nutr 26:1251-1260

6. Solomons NW, Rosenberg IH, Sandstead HH, Vo-Khactu KP 1977 Zinc deficiency in Crohn's disease. Digestion 16:87-95

7. Sandstead HH, Howard L 1982 Zinc deficiency in Crohn's disease. Nutr Rev 40:109-112

8. McClain C, Soutor C, Zieve L 1980 Zinc deficiency: a complication of Crohn's disease. Gastroenterology 78:272-279

9. Heimburger DC, Tamura T, Marks RD 1990 Rapid improvement in dermatitis after zinc supplementation in a patient with Crohn's disease. Am J Med 88:71-73

10. Krasovec M, Frenk E 1996 Acrodermatitis enteropathica secondary to Crohn's disease. Dermatology 193:361-363

11. Myung SJ, Yang SK, Jung HY, Jung SA, Kang GH, Ha HK, Hong WS, Min YI 1998 Zinc deficiency manifested by dermatitis and visual dysfunction in a patient with Crohn's disease. J Gastroenterol 33:876-879

12. Ainley CC, Cason J, Carlsson LK, Slavin BM, Thompson RP 1988 Zinc status in inflammatory bowel disease. Clin Sci (Lond) 75:277-283

13. Fernandez-Banares F, Mingorance MD, Esteve M, Cabre E, Lachica M, Abad-Lacruz A, Gil A, Humbert P, Boix J, Gassull MA 1990 Serum zinc, copper, and selenium levels in inflammatory bowel disease: effect of total enteral nutrition on trace element status. Am J Gastroenterol 85:1584-1589

14. Geerling BJ, Badart-Smook A, Stockbrugger RW, Brummer RJ 1998 Comprehensive nutritional status in patients with long-standing Crohn disease currently in remission. Am J Clin Nutr 67:919-926 
15. Kruis W, Rindfleisch GE, Weinzierl M 1985 Zinc deficiency as a problem in patients with Crohn's disease and fistula formation. Hepatogastroenterology 32:133-134

16. Mocchegiani E, Brignola C, Iannone P, Campieri M, Pasquali M, Lanfranchi GA Barbara L, Fabris N, Licastro F 1990 Levels of zinc and thymulin in plasma from patients with Crohn's disease. J Clin Lab Immunol 32:79-84

17. Nishi Y, Lifshitz F, Bayne MA, Daum F, Silverberg M, Aiges H 1980 Zinc status and its relation to growth retardation in children with chronic inflammatory bowel disease. Am J Clin Nutr 33:2613-2621

18. Sturniolo GC, Molokhia MM, Shields R, Turnberg LA 1980 Zinc absorption in Crohn's disease. Gut 21:387-391

19. Hessov I, Hasselblad C, Fasth S, Hulten L 1983 Zinc depletion after small-bowe resections for Crohn's disease. Hum Nutr Clin Nutr 37:353-359

20. Mulder TP, Verspaget HW, Janssens AR, de Bruin PA, Pena AS, Lamers CB 1991 Decrease in two intestinal copper/zinc containing proteins with antioxidant function in inflammatory bowel disease. Gut 32:1146-1150

21. Solomons NW, Rosenfield RL, Jacob RA, Sandstead HH 1976 Growth retardation and zinc nutrition. Pediatr Res 10:923-927

22. Geerling BJ, Badart-Smook A, Stockbrugger RW, Brummer RJ 2000 Comprehensive nutritional status in recently diagnosed patients with inflammatory bowel disease compared with population controls. Eur J Clin Nutr 54:514-521

23. Nakamura T, Higashi A, Takano S, Akagi M, Matsuda I 1988 Zinc clearance correlates with clinical severity of Crohn's disease. A kinetic study. Dig Dis Sci 33:1520-1524

24. Sandstrom B, Davidsson L, Bosaeus I, Eriksson R, Alpsten M 1990 Selenium status and absorption of zinc $(65 \mathrm{Zn})$, selenium $(75 \mathrm{Se})$ and manganese $(54 \mathrm{Mn})$ in patient with short bowel syndrome. Eur J Clin Nutr 44:697-703

25. Valberg LS, Flanagan PR, Kertesz A, Bondy DC 1986 Zinc absorption in inflammatory bowel disease. Dig Dis Sci 31:724-731

26. Abrams SA, Wen J, Stuff JE 1997 Absorption of calcium, zinc, and iron from breast milk by five- to seven-month-old infants. Pediatr Res 41:384-390

27. National Research Council Subcommittee on the Tenth Edition of the RDAs 1989 Recommended Dietary Allowances, 10th Ed. National Academy Press, Washington, $\mathrm{DC}$

28. Griffin IJ, King JC, Abrams SA 2000 Body weight-specific zinc compartmental masses in girls significantly exceed those reported in adults: a stable isotope study using a kinetic model. J Nutr 130:2607-2612

29. Abrams SA 1999 Using stable isotopes to assess mineral absorption and utilization by children. Am J Clin Nutr 70:955-964

30. Lowe NM, Shames DM, Woodhouse LR, Matel JS, Roehl R, Saccomani MP, Toffolo G, Cobelli C, King JC 1997 A compartmental model of zinc metabolism in healthy women using oral and intravenous stable isotope tracers. Am J Clin Nutr 65:18101819
31. Friel JK, Naake Jr VL, Miller LV, Fennessey PV, Hambidge KM 1992 The analysis of stable isotopes in urine to determine the fractional absorption of zinc. Am J Clin Nutr 55:473-477

32. Abrams SA, Sidbury JB, Muenzer J, Esteban NV, Vieira NE, Yergey AL 1991 Stable isotopic measurement of endogenous fecal calcium excretion in children. J Pediat Gastroenterol Nutr 12:469-473

33. Briefel RR, Bialostosky K, Kennedy-Stephenson J, McDowell MA, Ervin RB, Wright JD 2000 Zinc intake of the U.S. population: findings from the third National Health and Nutrition Examination Survey, 1988-1994. J Nutr 130:1367S-1373S

34. Guerinot ML 2000 The ZIP family of metal transporters. Biochim Biophys Acta 1465:190-198

35. Eide DJ 2004 The SLC39 family of metal ion transporters. Pflugers Arch 447:796800

36. Wang K, Zhou B, Kuo YM, Zemansky J, Gitschier J 2002 A novel member of a zinc transporter family is defective in acrodermatitis enteropathica. Am J Hum Genet 71:66-73

37. Kury S, Dreno B, Bezieau S, Giraudet S, Kharfi M, Kamoun R, Moisan JP 2002 Identification of SLC39A4, a gene involved in acrodermatitis enteropathica. Nat Genet 31:239-240

38. Kury S, Kharfi M, Kamoun R, Taieb A, Mallet E, Baudon JJ, Glastre C, Michel B, Sebag F, Brooks D, Schuster V, Scoul C, Dreno B, Bezieau S, Moisan JP 2003 Mutation spectrum of human SLC39A4 in a panel of patients with acrodermatitis enteropathica. Hum Mutat 22:337-338

39. Aggett PJ 1983 Acrodermatitis enteropathica. J Inherit Metab Dis 6:39-43

40. Cousins RJ 1996 Zinc. In: Ziegler EE, Filer Jr LJ (eds) Present Knowledge in Nutrition. ILSI Press, Washington DC, pp 293-306

41. Sullivan JF, Williams RV, Wisecarver J, Etzel K, Jetton MM, Magee DF 1981 The zinc content of bile and pancreatic juice in zinc-deficient swine. Proc Soc Exp Bio Med 166:39-43

42. Main AN, Hall MJ, Russell RI, Fell GS, Mills PR, Shenkin A 1982 Clinica experience of zinc supplementation during intravenous nutrition in Crohn's disease: value of serum and urine zinc measurements. Gut 23:984-991

43. Fleming CR, Huizenga KA, McCall JT, Gildea J, Dennis R 1981 Zinc nutrition in Crohn's disease. Dig Dis Sci 26:865-870

44. Pironi L, Miglioli M, Cornia GL, Ursitti MA, Tolomelli M, Piazzi S, Barbara L 1987 Urinary zinc excretion in Crohn's disease. Dig Dis Sci 32:358-362

45. Institute of Medicine, Food and Nutrition Board's Standing Committee on the Scientific Evaluation of Dietary Intervals 2001 Zinc. In: Dietary Reference Intervals for Vitamin A, Vitamin K, Arsenic, Boron, Chromium, Copper, Iodine, Iron, Manganese, Molydbenum, Nickel, Silicon, Vandium and Zinc. National Academy Press, Washington DC, pp 442-501 